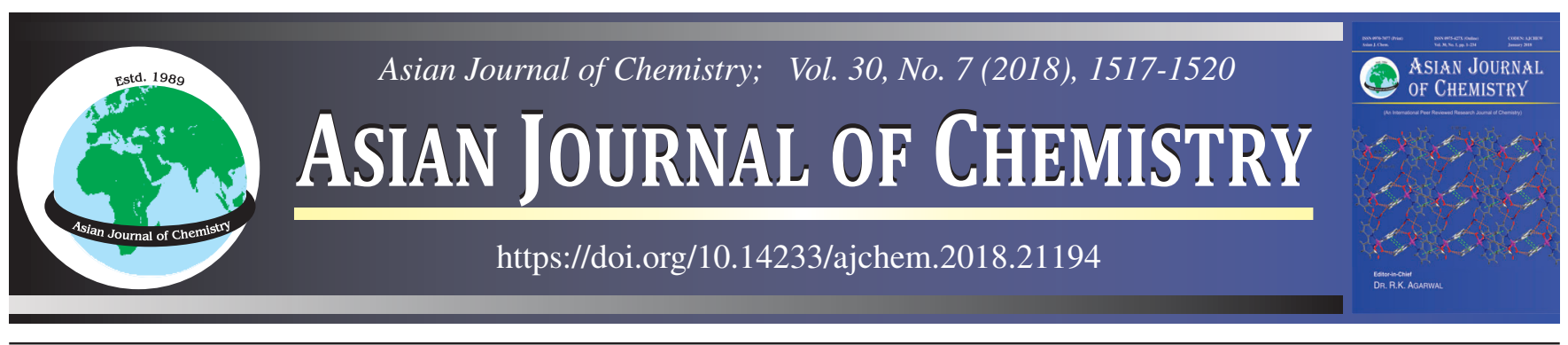

\title{
Batch Leaching Studies of Penoxsulam Herbicide in Two Different Soils
}

\author{
Monika Dayanand ${ }^{1, *}$, Anjana Srivastava ${ }^{1}$, Gajan Pal Singh $^{1}$ and Prakash C. Srivastava ${ }^{2}$
}

${ }^{1}$ Department of Chemistry, College of Basic Sciences and Humanities, Govind Ballabh Pant University of Agriculture and Technology, Pantnagar263145 , India

${ }^{2}$ Department of Soil Science, College of Agriculture, Govind Ballabh Pant University of Agriculture and Technology, Pantnagar-263 145 India

*Corresponding author: E-mail: monika.dayanand10@gmail.com

Penoxsulam possesses a leaching tendency in soil, therefore a research study was undertaken to assess the portability of penoxulam herbicide, in two soils of varying characteristics at two application rates $\left(0.5\right.$ and $\left.1.0 \mu \mathrm{g} \mathrm{g}^{-1}\right)$ by batch method. The presence of penoxsulam was very low in the first and third leachate but it was determined in high amount in the second leachate, which was collected after $72 \mathrm{~h}$ of leaching initiation, indicating a high potential of this herbicide leaching. The residues of penoxsulam in leachate of acidic soil were slightly lower than that of neutral soil probably because of higher stability of the herbicide at low $\mathrm{pH}$. (

| Keywords: Penoxsulam, Triazolopyrimidine sulfonamide, Leaching, Soil, Leachate.

\section{INTRODUCTION}

Leaching is a physical process by which chemicals (here pesticides) move downward from the surface layers of the soil, where they initially reside after regular application, in the soil vadose zone and move in the long run to groundwater. It is a mass transport process conveyed by the downhill movement of water following rain or irrigation. For hazard evaluation of these chemicals, it is vital to estimate their potential for transformation in soil and for movement (leaching) into more profound soil layers and eventually in the ground water. Leaching of pesticides to ground water is a serious threat as the ground water is the real wellspring of drinking water. Once released into the environment, pesticides can travel through hydrologic system to streams and groundwater, where they may effectively affect humans, aquatic as well as wild life.

Penoxsulam [2-(2,2-difluoroethoxy)-N-(5,8-dimethoxy$[1,2,4]$ triazolo[1,5-c]pyrimidin-2-yl)-6-(trifluoromethyl)benzenesulfonamide] is a new triazolopyrimidine sulfonamide (TSA) herbicide, enrolled in United States in 2004 and developed by Dow Agro Sciences under the trade name 'Granite'. The herbicide is utilized for the control of annual grasses, aquatic plants, sedges and broadleaf weeds in rice culture with good crop selectivity and high herbicidal activity at low application rate of 20-25 g a.i./ha [1,2]. It is post-emergence, acetolactate synthase (ALS) inhibitor, used as a foliar spray on dry-seeded rice crops or as a granular formulation on water-seeded rice crops [3]. Triazolopyrimidine sulfonamide herbicides have been classified amongst potential leachers in soil.

The most imperative physical properties that decide the leaching of agrochemicals are the water solubility and sorption coefficient. The water solubility of penoxsulam is highly $\mathrm{pH}$ reliant as $5.7 \mathrm{mg} \mathrm{L}^{-1}$ at $\mathrm{pH} 5,410 \mathrm{mg} \mathrm{L}^{-1}$ at $\mathrm{pH} 7$, and $1460 \mathrm{mg}$ $\mathrm{L}^{-1}$ at $\mathrm{pH} 9$ and a vapour pressure of $9.5 \times 10^{-14} \mathrm{~Pa}$ at $25^{\circ} \mathrm{C}$ [4]. The reported soil sorption coefficient (low) of penoxsulam (0.2-5.1) demonstrates its high mobility in the environment $[1,5]$. Consequently, there is a high plausibility of its transportation from the fields to water bodies but the mobility varies between various TSA herbicides. Residues of penoxsulam in soil are low and parenthetic after application to flooded and non-flooded rice fields [4]. However, cloransulam-methyl, another member of TSA group was held in the soil surface layer $(0-15 \mathrm{~cm})$ for long after application to soybean crops in spite of strong leaching conditions at test sites [6].

Penoxsulam is highly mobile but not very persistent in both water and soil [7]. Its dissipation in water could be the after effect of photolysis [8]. The herbicide is considered especially poisonous to aquatic plants and its presence even at low concentrations in surface waters entail an inadmissible hazard for aquatic plants and also for the soil microbial population [9]. In soils, a previous study conducted in our lab on dissipation of penoxsulam at two application rates $\left(0.5\right.$ and $\left.1.0 \mu \mathrm{g} \mathrm{g}^{-1}\right)$ revealed that half lives of penoxsulam in soils ranged between 3.48 and 3.57 days at lower rate and 4.1 and 4.17 days at higher 
rate of application and the herbicide was below detectable limit $\left(\mathrm{BDL}<0.003 \mu \mathrm{g} \mathrm{g}^{-1}\right)$ within 45 days [10].

Both batch and column leaching studies are essential to assess the leaching behavior of pesticides and evaluate possible consequences on sensitive non target terrestrial plants through irrigation with surface water. Hence, the present investigation was undertaken to study the leaching behavior of penoxsulam herbicide in two different soils by batch method to foreseen the potential danger of ground water contamination.

\section{EXPERIMENTAL}

Two different soils ( $0-25 \mathrm{~cm}$ profundity) A and B, belonging to Mollisol order were collected from Pattharchatta, G.B. Pant University campus. The soils were characterized for their properties (texture, $\mathrm{pH}, \mathrm{EC}$ and organic carbon) by standard methods in Department of Soil Science, College of Agriculture at G.B. Pant University of Agriculture and Technology, Pantnagar, India

The colourless (white crystalline compound) analytical grade penoxsulam (purity 99\%) was provided by Dow Agro Sciences India Pvt. Ltd. Company, Mumbai, India. The chemicals used in this study were of analytical and HPLC grade obtained from E. Merck (India) Ltd. Double distilled water, prepared in research laboratory by quartz distillation unit was used for preparing solutions.

Soil samples were air dried in shade, pulverized with wooden roller and passed through sieve containing openings of $2 \mathrm{~mm}$ width. The physicochemical properties of the soils, for example, $\mathrm{pH}$, electrical conductivity and percentage of organic carbon were analyzed by standard analytical methods [11]. A stock solution of penoxsulam $100 \mu \mathrm{g} \mathrm{mL}^{-1}$ was prepared in acetonitrile and serial dilutions $\left(0-5 \mu \mathrm{g} \mathrm{mL}^{-1}\right)$ were made. Thereafter, a calibration curve for penoxsulam was plotted between peak area and different concentrations of penoxsulam.

The leaching studies were performed in 14 equivalent measured dispensable glasses $10.5 \mathrm{~cm}$ (length) $\times 7.3 \mathrm{~cm}$ (i.d.). The glasses were perforated at the base and provided with a glass wool and sand pack. For screening the vertical movement and leaching losses of penoxsulam, $300 \mathrm{~g}$ of each soil samples were fortified with 0.5 and $1.0 \mu \mathrm{g} \mathrm{g}^{-1}$ penoxsulam standards individually and $45 \mathrm{~mL}$ distilled water, to keep the soil moisturized. Afterwards, equal amount of fortified soils $(100 \mathrm{~g})$ of both the types were packed in the glasses in triplicate. One glass each for both the soils was kept as control i.e. soil having $15 \mathrm{~mL}$ water only and no penoxsulam. Leaching was initiated by providing $210 \mathrm{~mL}$ distilled water head over the glasses to maintain $5 \mathrm{~cm}$ water layer on the top of the soil and first leachate water got collected in beakers in $30 \mathrm{~min}(0 \mathrm{~h})$. After $72 \mathrm{~h}, 150 \mathrm{~mL}$ of distilled water was again added to each soil and $2^{\text {nd }}$ leachate water was collected as before. Similarly, $3^{\text {rd }}$ leachate water was also collected after $72 \mathrm{~h}$ of second leaching. On the whole, three fractions of leachate water were collected in each case.

Extraction and clean-up of penoxsulam from leachate and soil samples: Leachate $(50 \mathrm{~mL})$ were taken in separating funnels and dichloromethane $(50 \mathrm{~mL})$ was added to them. The contents were shaken for $10 \mathrm{~min}$ and partitioned. The lower organic layer from each funnel was isolated and the aqueous layer was once again partitioned with $50 \mathrm{~mL}$ of dichloromethane. The combined dichloromethane concentrate was collected and passed through anhydrous sodium sulfate packed in $30 \mathrm{~cm}$ columns. Filtrate was collected, pooled and dried at $40{ }^{\circ} \mathrm{C}$ on a flash evaporator to close dryness. Finally, the residue was dissolved in $2 \mathrm{~mL}$ of HPLC grade acetonitrile.

After consummation of the leaching cycle, the herbicide was also extracted from each soil according to the method of Saha et al. [12] with slight modifications. Equal amounts (10 g) of soils were taken in conical flasks and $20 \mathrm{~mL}$ of acetonitrile was added to each. The contents of each flask were shaken for $30 \mathrm{~min}$ and the upper organic layer was decanted and filtered. The soil of each conical flask was once again shaken for $15 \mathrm{~min}$ with $15 \mathrm{~mL}$ of acetonitrile and the upper organic phase was isolated and consolidated with the previous fraction. The assorted extract was collected in round bottom flask and dried at $40{ }^{\circ} \mathrm{C}$ on a rotary evaporator till it reduced to $2 \mathrm{~mL}$. It was then dissolved in $50 \mathrm{~mL}$ of distilled water, transferred to the separating funnel and partitioned with $50 \mathrm{~mL}$ of dichloromethane twice. The combined dichloromethane extract was collected and passed through $30 \mathrm{~cm}$ column which was packed with anhydrous sodium sulfate to remove traces of moisture. Filtrate was pooled and dried at $40^{\circ} \mathrm{C}$ on a flash evaporator to close dryness. The final volume was made up with $2 \mathrm{~mL}$ of acetonitrile and filtered through $0.22 \mu \mathrm{m}$ PTFE disc filter for HPLC analysis of penoxsulam.

In order to establish the reliability of the analytical method adopted and to know the efficiency of the steps employed for the extraction and analysis of penoxsulam in water and soils, recovery experiments were undertaken. For this, $50 \mathrm{~mL}$ of water was fortified with 1.0 and $2.0 \mu \mathrm{g} \mathrm{mL}^{-1}$ and $50 \mathrm{~g}$ of soil samples in duplicate were fortified with 1.0 and $2.0 \mu \mathrm{g} \mathrm{g}^{-1}$ of analytical grade penoxsulam standard. The samples were extracted and cleaned up following the procedure referred in preceding sections.

Analysis of samples using RP-HPLC: For the analysis of penoxsulam residues Dionex Ultimate 3000 High Performance Liquid Chromarogaph (HPLC) containing C18 column, $(250 \times 4.6 \mathrm{~mm}$ i.d., $5 \mu \mathrm{m})$ under isocratic mode, with $100 \%$ $\mathrm{CH}_{3} \mathrm{CN}$ as mobile phase and $\mathrm{UV}$ detection $(230 \mathrm{~nm})$ at a flow rate of $0.7 \mathrm{~mL} \mathrm{~min}^{-1}$ and the injection volume of $20 \mu \mathrm{L}$ was used. Under the above conditions, the retention time of penoxsulam was 4 min (Fig. 1).

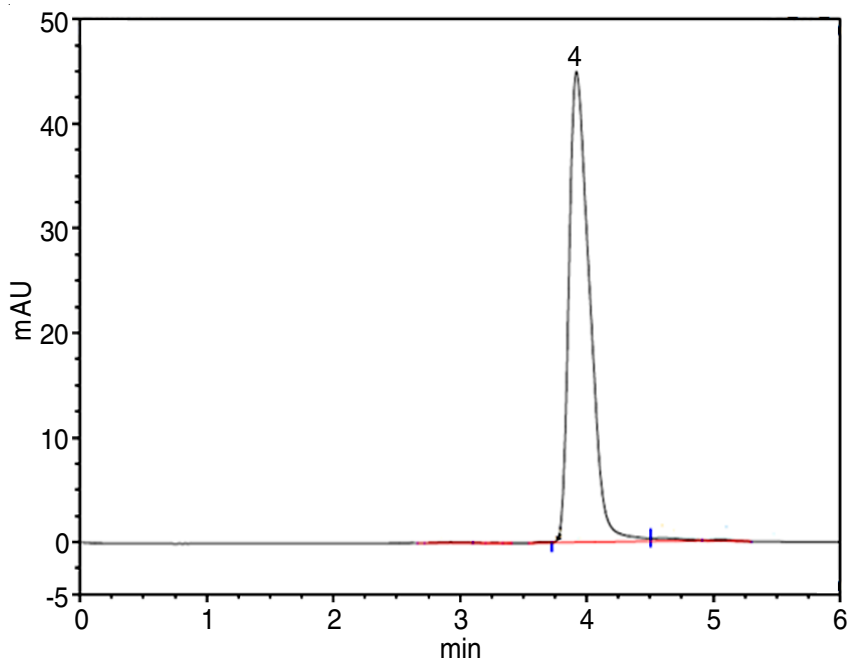

Fig. 1. Standard chromatogram of penoxsulam herbicide 


\section{RESULTS AND DISCUSSION}

Two soils collected for leaching studies were silty clay loam in texture with soil A having a pH of 6.86 , electrical conductivity $110 \mu \mathrm{S} \mathrm{cm}^{-1}$ and organic carbon content of $0.722 \%$ whereas soil B had a $\mathrm{pH}$ of 5.35 , electrical conductivity 250 $\mu \mathrm{S} \mathrm{cm}^{-1}$ and organic carbon content of $0.779 \%$, respectively.

The per cent recovery estimations of penoxsulam from the water and two soil samples (A and B) varied from $93.0 \pm$ 0.7 to $89.0 \pm 0.8 \%$ and $87.5 \pm 1.4 \%$ at higher fortification rate and $91.3 \pm 0.9$ to $84.9 \pm 0.7 \%$ and $82.9 \pm 1.8 \%$ at lower fortification rates, respectively (Tables 1 and 2). The LOQ and LOD values calculated on the basis of $\mathrm{S} / \mathrm{N}$ ratio for penoxsulam were 0.008 and $0.003 \mu \mathrm{g} \mathrm{g}^{-1}$, respectively.

TABLE-1

RECOVERY (\%) OF PENOXSULAM FROM WATER AND SOIL SAMPLES AT HIGHER FORTIFICATION RATE

\begin{tabular}{cccc}
\hline Samples & Water & Soil A & Soil B \\
\hline 1 & 93.8 & 89.9 & 87.6 \\
2 & 92.3 & 89.0 & 86.0 \\
3 & 93.0 & 88.3 & 88.8 \\
Mean \pm S.D. & $93.0 \pm 0.7$ & $89.0 \pm 0.8$ & $87.5 \pm 1.4$ \\
\hline
\end{tabular}

TABLE-2

RECOVERY (\%) OF PENOXSULAM FROM WATER AND SOIL SAMPLES AT LOWER FORTIFICATION RATE

\begin{tabular}{cccc}
\hline Samples & Water & Soil A & Soil B \\
\hline 1 & 92.3 & 85.7 & 84.5 \\
2 & 91.0 & 84.2 & 83.3 \\
3 & 90.6 & 85.0 & 81.0 \\
Mean \pm S.D. & $91.3 \pm 0.9$ & $84.9 \pm 0.7$ & $82.9 \pm 1.8$ \\
\hline
\end{tabular}

Statistical analysis: The data obtained were subjected to statistical treatment by analysis of variance (ANOVA) for the three factor randomized block design with the help of SPSS software and critical difference values were obtained by using STPR15 software. Soil, pesticide concentration and time were considered as first, second and third factors, respectively. Standard error of mean was calculated in each case. Critical difference (CD) calculated at $5 \%$ level of significance was used for the comparison of differences among the treatment means.

The residues of the herbicide in various fractions of leachate are shown in Table-3 in both the soils. Minor portion of the herbicide could be detected $\left(0.120\right.$ to $0.112 \mu \mathrm{g} \mathrm{g}^{-1}$ at lower fortification rate and 0.236 to $0.219 \mu \mathrm{g} \mathrm{g}^{-1}$ at higher fortification rate) in the first fraction of leachate whereas major amount of the herbicide was found in the second fraction of leachate i.e. 0.346 to $0.339 \mu \mathrm{g} \mathrm{g}^{-1}$ at lower fortification rate and 0.689 to $0.668 \mu \mathrm{g} \mathrm{g}^{-1}$ at higher fortification rate in soils $\mathrm{A}$ and $\mathrm{B}$, respectively. Third fraction of the leachate contained the minimum amount of herbicide i.e. 0.033 to $0.023 \mu \mathrm{g} \mathrm{mL}^{-1}$ at lower fortification rate and 0.060 to $0.048 \mu \mathrm{g} \mathrm{mL}^{-1}$ at higher fortification rate from both the soils. Hence, the maximum amount of the herbicide was noticed in the leachate collected after $72 \mathrm{~h}$ in both the soils (Fig. 2).

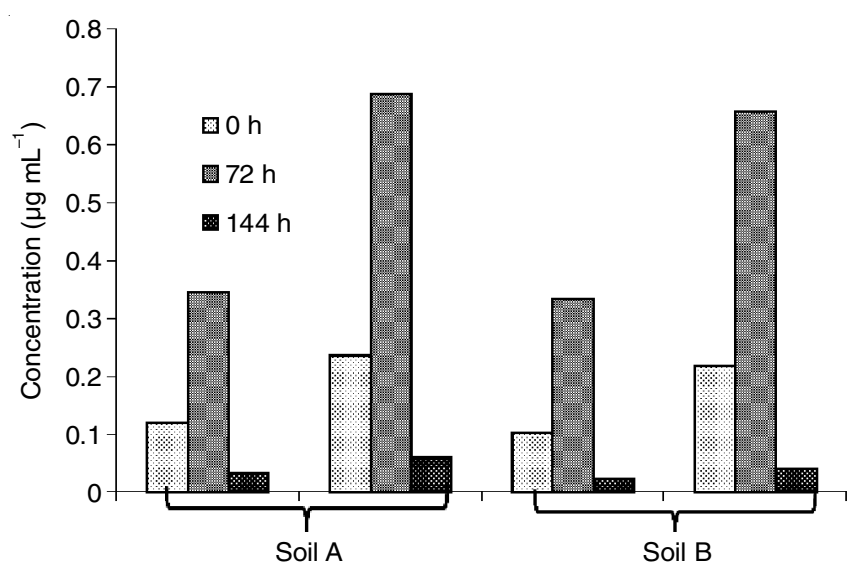

Fig. 2. Penoxsulam residues present in different leachate @ 0.5 and $1.0 \mu \mathrm{g}$ $\mathrm{mL}^{-1}$ in soil A and B

The herbicide mobility in soils varies between various members of TSA herbicides. Residues of penoxsulam in soil were low and evanescent after application to flooded and non flooded rice fields [4]. However, cloransulam-methyl, another member of TSA was significantly found in the soil surface layer $(0-15 \mathrm{~cm})$ after application to soybean crops in spite of strong leaching conditions at test sites [6]. The model PRZM2 (Pesticide Root Zone Modeling) suggests that cloransulammethyl is potentially mobile in finer textured soils with $<1.5 \%$ organic matter. The concentration of flumetsulam in three Mississippi soils of varying characteristics was primarily limited to the upper $8 \mathrm{~cm}$ of soil after 84 days of treatment [13]. Flumetsulam residues were detectable but low in the $8-15 \mathrm{~cm}$ surface layer and were never detected in the $15-20 \mathrm{~cm}$ layer, during the cropping period. The results revealed that leaching is not significant dissipation route because flumetsulam strongly adsorbed to the soil [14]. The reported half life of flumetsulam in soil ranges from 30 to 60 days at $\mathrm{pH}$ 6-7 [15]. A runoff study revealed that less than $6 \%$ of diclosulam applied to peanut fields would be lost from severe fall. Of the total diclosulam runoff, $97 \%$ was transported off the field by water, with $<3 \%$ associated with the sediment [16]. Soil aging effects, resulting in increased adsorption, can contribute to the limited mobility of diclosulam [17,18], clorasulam-methyl [6] and florasulam in soils [19].

The residues of penoxsulam in leachate of acidic soil $(\mathrm{pH}$ 5.35) were lower as compared to the leachate of neutral soil ( $\mathrm{pH}$ 6.86). It has already been reported that the water solubility

TABLE-3

CONCENTRATION OF PENOXSULAM FROM BOTH THE SOILS AFTER THREE DIFFERENT TIMES

\begin{tabular}{cccc|ccc}
\hline & \multicolumn{3}{c|}{ Leachate lower dose $\left(0.5 \mu \mathrm{g} \mathrm{g}^{-1}\right)$} & \multicolumn{3}{c}{ Leachate higher dose $\left(1.0 \mu \mathrm{gg} \mathrm{g}^{-1}\right)$} \\
\cline { 2 - 7 } & $0 \mathrm{~h}$ & $72 \mathrm{~h}$ & $144 \mathrm{~h}$ & $0 \mathrm{~h}$ & 0.689 & $144 \mathrm{~h}$ \\
\hline Soil A & 0.120 & 0.346 & 0.033 & 0.236 & 0.060 & 0.668 \\
Soil B & 0.112 & 0.339 & 0.023 & 0.219 & 0.002 & 0.003 \\
SEm & 0.001 & 0.002 & 0.002 & 0.006 & 0.006 & 0.009 \\
CD at 5\% & 0.004 & 0.004 & 0.005 &
\end{tabular}

Significant at $* \mathrm{p} \leq 0.05$ 
of penoxsulam in acidic medium is lower than in neutral medium [4]. In case of soils too, penoxsulam has been confirmed to be more stable in acidic soil in comparison to neutral soil [20]. The residues of penoxsulam analyzed in soils after collecting the three leachates were found to be below detectable limit $\left(\mathrm{BDL}<0.003 \mu \mathrm{g} \mathrm{g}^{-1}\right)$ in both the soils at both application rates.

\section{Conclusion}

From the results, it can be concluded that penoxsulam does not get strongly adsorbed on to the soil surface because of its ability to leach out from soil. Thus, leaching could be the principal phenomena responsible for penoxsulam dissipation. Column and field studies need to be undertaken for further confirmation of leaching behaviour of penoxsulam. The results of this study suggest that the mobility of penoxsulam was higher as compared to other members of the triazolopyrimidine sulfonamide family.

\section{REFERENCES}

1. W.A. Kleschick, B.C. Gerwick, C.M. Carson, W.T. Monte and S.W. Snider, J. Agric. Food Chem., 40, 1083 (1992); https://doi.org/10.1021/jf00018a035.

2. S. Baskaran, D.R. Lauren and P.T. Holland, J. Chromatogr. A, 746, 25 (1996); https://doi.org/10.1016/0021-9673(96)00295-6.

3. T.W. Jabusch and R.S. Tjeerdema, J. Agric. Food Chem., 54, 5962 (2006); https://doi.org/10.1021/jf0606454.

4. D.W. Roberts, J.A. Knuteson and R. Jackson, The Dissipation of Penoxsulam in Flooded Rice Fields, In: Pesticides in Air, Plant, Soil \& Water Systems: XII Symposium Pesticide Chemistry, Piacenza, Italy, pp 349 (2003).

5. T.W. Jabusch and R.S. Tjeerdema, J. Agric. Food Chem., 53, 7179 (2005); https://doi.org/10.1021/jf050767g.

6. I.J. van Wesenbeeck, J.M. Zabik, J.D. Wolt, G.A. Bormett and D.W. Roberts, J. Agric. Food Chem., 45, 3299 (1997); https://doi.org/10.1021/jf9702050.
7. T.W. Jabusch and R.S. Tjeerdema, Rev. Environ. Contam. Toxicol., 193, 31 (2008); https://doi.org/10.1007/978-0-387-73163-6_2.

8. M. Kogan, M. Araya and C. Alister, Pest Manag. Sci., 68, 399 (2012); https://doi.org/10.1002/ps.2276.

9. S. Sondhia, S. Rajput, R.K. Varma and A. Kumar, Appl. Soil Ecol., 105, 196 (2016);

https://doi.org/10.1016/j.apsoil.2016.03.010.

10. Monika, A. Srivastava, A. Suyal and P.C. Srivastava, Bull. Environ. Contam. Toxicol., 99, 470 (2017); https://doi.org/10.1007/s00128-017-2171-x.

11. M.L. Jackson, Soil Chemical Analysis. Prentice Hall, Inc., New Jersey, USA. pp. 38-226 (1958).

12. S. Saha, S.B. Singh and G. Kulshrestha, J. Environ. Sci. Health B, 38, 337 (2003); https://doi.org/10.1081/PFC-120019900.

13. G.P. Murphy and D.R. Shaw, Weed Sci., 45, 564 (1997).

14. J. Rouchaud, O. Neus, H. Eelen and R. Bulcke, Meded. Fac. Landbouwwet. Rijksuniv. Gent., 67, 401 (2002).

15. B.C. Gerwick and W.A. Kleschick, Weed Sci. Abstr, 31, 28 (1991).

16. I.J. van Wesenbeeck, A.L. Peacock and P.L. Havens, J. Environ. Qual., 30, 553 (2001); https://doi.org/10.2134/jeq2001.302553x

17. R.N. Yoder, M.A. Huskin, L.M. Kennard and J.M. Zabik, J. Agric. Food Chem., 48, 4335 (2000); https://doi.org/10.1021/jf9911848.

18. J.M. Zabik, I.J. van Wesenbeeck, A.L. Peacock, L.M. Kennard and D.W. Roberts, J. Agric. Food Chem., 49, 3284 (2001); https://doi.org/10.1021/jf001236p.

19. M.S. Krieger, F. Pillar and J.A. Ostrander, J. Agric. Food Chem., 48, 4757 (2000); https://doi.org/10.1021/jf000009k.

20. S.K. Pramanik, B. Kanrar, S. Dutta and A. Bhattacharyya, eds.: B. Marambe, U.R. Sangakkara, W.A.J.M. De Costa and A.S.K. Abeysekara, Laboratory Simulated Studies on the Persistence Behavior of "Penoxsulam 24 SC" in Soils of Different Agro-climatic Zones in India, Proceedings of $21^{\text {st }}$ Asian Pacific Weed Science Society Conference, Colombo, Sri Lanka (2007). 